\title{
MATHEMATICAL MODELING OF PERIFUSION CELL CULTURE EXPERIMENTS ON GNRH SIGNALING
}

\author{
N Ezgi Temamogullari ${ }^{\mathrm{a}, *}$, H Frederik Nijhout ${ }^{\mathrm{b}}$, Michael C Reed ${ }^{\mathrm{a}}$ \\ ${ }^{a}$ Department of Mathematics, Duke University, Durham, North Carolina \\ ${ }^{b}$ Department of Biology, Duke University, Durham, North Carolina
}

\begin{abstract}
The effects of pulsatile GnRH stimulation on anterior pituitary cells are studied using perifusion cell cultures, where constantly moving culture medium over the immobilized cells allows intermittent GnRH delivery. The LH content of the outgoing medium serves as a readout of the GnRH signaling pathway activation in the cells. The challenge lies in relating the LH content of the medium leaving the chamber to the cellular processes producing LH secretion. To investigate this relation we developed and analyzed a mathematical model consisting of coupled partial differential equations describing LH secretion in a perifusion cell culture. We match the mathematical model to three different data sets and give cellular mechanisms that explain the data. Our model illustrates the importance of the negative feedback in the signaling pathway and receptor desensitization. We demonstrate that different LH outcomes in oxytocin and GnRH stimulations might originate from different receptor dynamics and concentration. We analyze the model to understand the influence of parameters, like the velocity of the medium flow or the fraction collection time, on the LH outcomes. We show that slow velocities lead to high LH outcomes. Also, we show that fraction collection times, which do not divide the GnRH pulse period evenly, lead to irregularities in the data. We examine the influence of the rate of binding and dissociation of GnRH on the GnRH movement down the chamber. Our model serves as an important tool that can help in the design of perifusion experiments and the interpretation of results.
\end{abstract}

Keywords: Mathematical Model, Perifusion Cell Culture, GnRH, LH

\footnotetext{
* Corresponding author

Email addresses: ezgi@math.duke.edu (N Ezgi Temamogullari ), hfn@duke.edu (H Frederik Nijhout), reed@math.duke.edu (Michael C Reed)
} 


\section{INTRODUCTION}

Gonadotropin Releasing Hormone (GnRH) is the master regulator of reproductive physiology. It is secreted from the hypothalamus in pulses and stimulates the anterior pituitary gonadotroph cells via $\mathrm{GnRH}$ receptors (GnRH-R). This stimulation leads to synthesis and secretion of the gonadotropins Luteinizing Hormone (LH) and Follicle Stimulating Hormone (FSH), which regulate sex steroid hormone synthesis and progression through the menstrual cycle.

The influence of the pulsatile GnRH signal on pituitary cells can be studied in vitro with perifusion cell cultures $[1,2,3,4,5,6,7,8]$, in which the cells are immobilized in a cell chamber, through which the culture medium flows continuously at a constant rate (see Figure 1). GnRH is introduced into the cell chamber along with the fresh medium through the inlet, where the concentration of GnRH entering the chamber per unit time is controlled. The effluent is collected in fixed time intervals and these fractions are analyzed for their LH content. GnRH moves down the chamber with the moving fluid and as it travels, it binds to GnRH-Rs on the cells activating a signaling cascade. The activation of the signaling cascade causes LH release from the cells into the cell chamber and the secreted LH travels with the flowing medium towards the outlet.

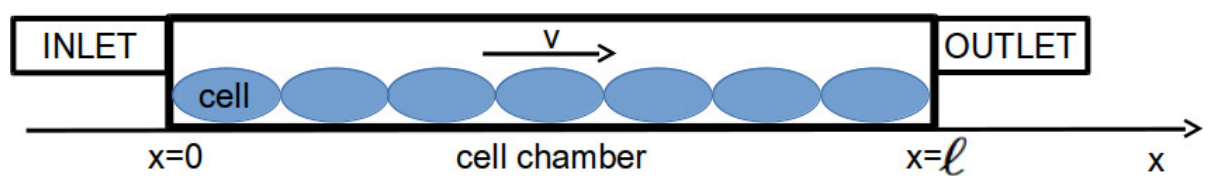

Figure 1: Perifusion Cell Culture Diagram. The blue circles represent the cells immobilized in the cell chamber. The culture medium enters the chamber through the inlet, flows with velocity $v$ through the chamber and leaves the chamber through the outlet. The length of the cell chamber is $\ell$.

The GnRH signaling pathway in gonadotrophs involves activation of different mitogen-activated protein kinases (MAPK) and MAPK phosphatases (MKP) $[9,10,11,12]$. MAPKs become activated by phosphorylation and active MAPKs induce gonadotropin synthesis and secretion. Active MKPs inactivate MAPKs by dephosphorylating them, and thus, MKPs constitute an important negative feedback mechanism $[13,14,15,16]$. GnRH-R desensitization constitutes another negative feedback mechanism $[17,18]$. All of these mechanisms, which are indicated schematically in Figure 2, are part of our mathematical model. The GnRH signaling pathway has other downstream components that are not included in the model (See Discussion).

Abbreviations: Gonadotropin Releasing Hormone (GnRH); GnRH Receptor (GnRH-R); Luteinizing Hormone (LH); Follicle Stimulating Hormone (FSH); Mitogen-Activated Protein Kinases (MAPK); MAPK phosphatases (MKP) 


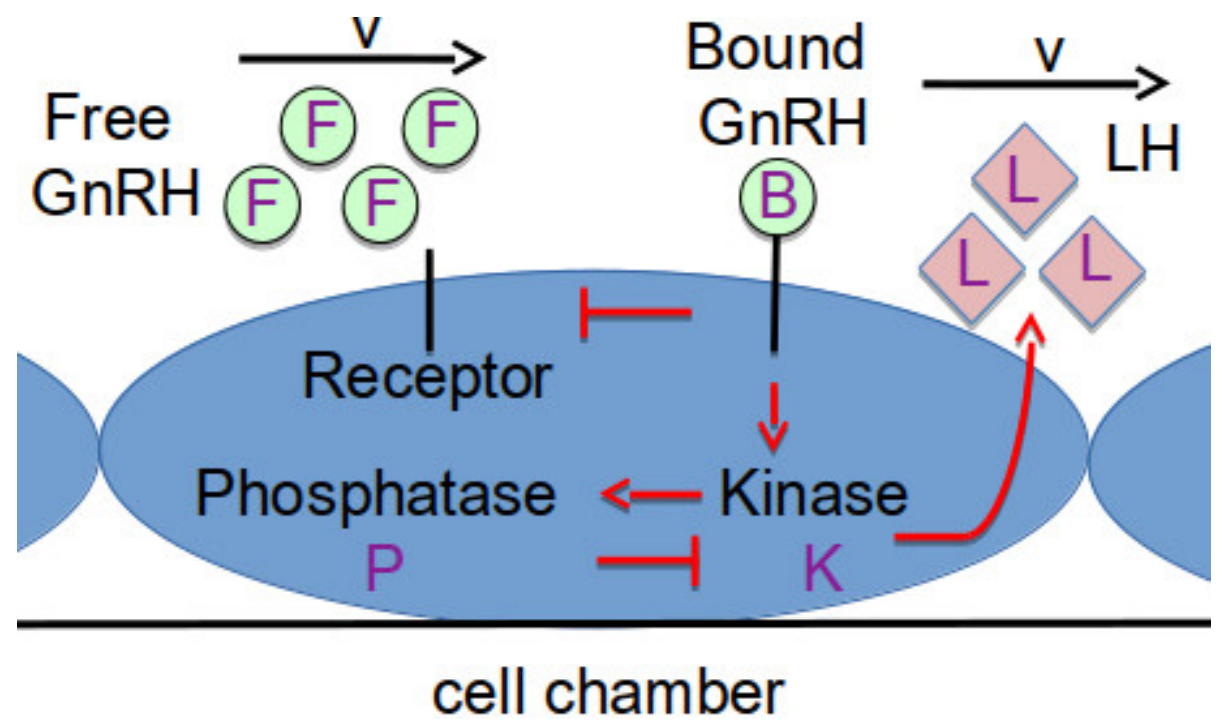

Figure 2: Schema of the interactions involved in the mathematical model. Free GnRH, F, represents the GnRH molecules that are not bound to the receptor and are moving with the fluid in the chamber. Bound GnRH, B, denotes GnRH bound to a receptor. Kinase, $\mathrm{K}$, is the activated kinase and phosphatase, $\mathrm{P}$, is the activated phosphatase. LH, L, denotes LH molecules that are secreted from the cell into the chamber. There are two negative feedback loops in the network: inactivation of kinases by the phosphatases and receptor desensitization caused by bound GnRH.

The interesting question is how to use the effluent LH content to understand the cellular processes producing LH. Diverse mathematical models of the GnRH signaling pathway have been developed for analyzing perifusion cell culture data $[19,20,21,22,23,24,25]$. However, to the best of our knowledge, almost all of them are restricted to systems of ordinary differential equations lacking the spatial component of the experimental setup. As we will see, spatial parameters such as the length of the chamber and the velocity of the medium affect significantly the experimental results. Smith et al. analyze partial differential equations describing how a chemical signal distorts as it passes through a chamber in [19]. However, they do not model the signal transduction in the cells in a perifusion chamber.

In this paper we present a novel mathematical model of the LH secretion from gonadotroph cells in a perifusion cell culture. The model consists of a system of coupled partial differential equations describing the movement of $\mathrm{GnRH}$ and LH in the cell chamber and the dynamics of total receptors, kinases and phosphatases in the cells. Figure 3 shows a sample simulation depicting the cell chamber at a fixed time. The $\mathrm{x}$-axis shows the position in the chamber and the y-axis shows the concentrations of free GnRH (cyan), bound GnRH (green), total receptors (magenta), active kinase (red), active phosphatase (blue) and 


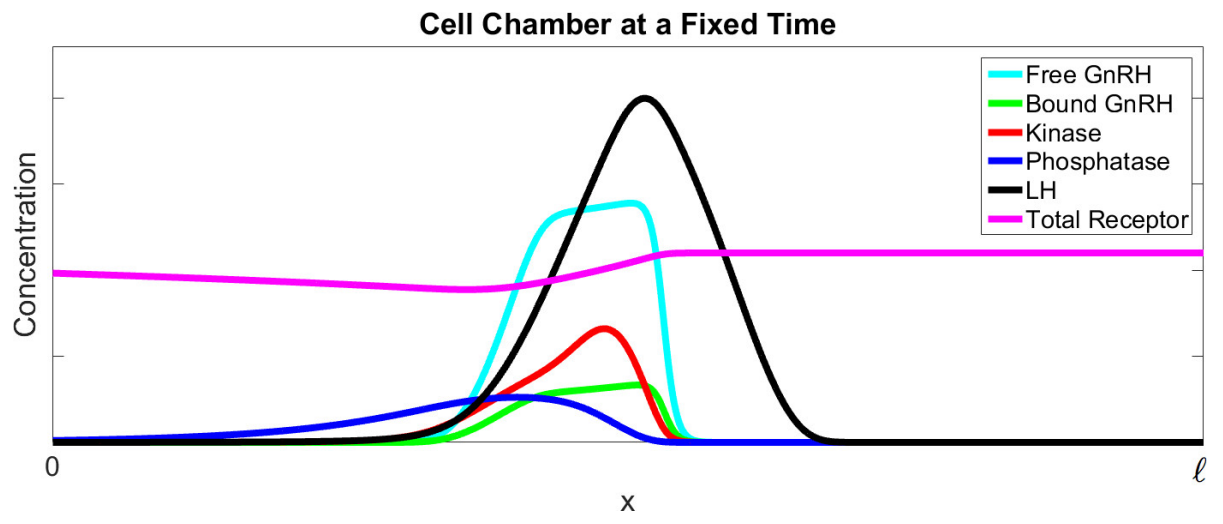

Figure 3: Simulation of the Perifusion Cell Chamber at a Fixed Time. The x-axis is the position in the cell chamber from 0 to $\ell$; the $y$-axis is the concentration of the species in arbitrary units.

LH (black). As the free GnRH (cyan) moves down the chamber, it binds to the GnRH-Rs forming bound GnRH (green) and activates the kinases (red). This leads to both activation of phosphatases (blue) and the release of LH (black) into the chamber. Released LH moves down the chamber with the medium. In this simulation LH moves faster than the free and bound GnRH, since the movement of GnRH is retarded by its interaction with the receptors. Bound GnRH, in addition to activating the signaling cascade, leads to a decrease in the total receptor concentration (magenta) via desensitization of the receptor. As we will see, the mathematical model presented in this paper aids in understanding and interpreting perifusion cell culture data by connecting the dynamics of the LH outcome to the cellular processes generating it. The model also shows how the parameters controlled by the experimenters, like the velocity of the fluid flow, the cell concentration in the chamber, the GnRH pulse characteristics, affect the experimental outcomes (See Results).

In Section 2 we describe the mathematical model. In Section 3.1 we compare the mathematical model to three different data sets consisting of the LH content of the fractions collected from the cell chamber. The first data set, taken from [26], is a finely sampled data, where LH shows a characteristic triphasic response. We use the first data set to estimate the model parameters and we explain which cellular interactions might be underlying the shape of the LH output. The second data set [27] is collected over a longer time course, where multiple GnRH pulses are introduced into the chamber. The same parameters used in the first data set reproduce the second data set; thus, the second data set serves as a cross validation. Also, using the second data set we show how the length of the fraction collection time affects the regularity of the data. The third data set [28] compares oxytocin and GnRH action on pituitary cells. We use a different set of parameters for the third data set, which is biologically 
reasonable, since the cell type used is different than the first two data sets. We matched the parameters to $\mathrm{GnRH}$ stimulation data and recovered the oxytocin stimulation outcome just by changing one or two parameters related to the receptor dynamics, showing a possible mechanism explaining the different outcomes in these two cases. In Section 3.2, we conduct in silico experiments to investigate the importance of key parameters. First, we show how the velocity of the medium flow affects the LH outcome. Next, we focus on the GnRH movement in the chamber and describe how this movement depends on the binding rate of $\mathrm{GnRH}$ to its receptor, the dissociation rate of bound $\mathrm{GnRH}$ from the receptor and the total GnRH-R concentration. Finally, we discuss how the LH outcome per GnRH amount supplied to the chamber depends on the GnRH pulse characteristics.

\section{MATHEMATICAL MODEL}

The mathematical model is a system of partial differential equations for the following variables: the free GnRH, $F(x, t)$; GnRH bound to its receptor, $B(x, t)$; total receptor concentration, $R(x, t)$; active kinase, $K(x, t)$; active phosphatase, $P(x, t)$; and the secreted LH, $L(x, t)$. For all of these variables the units are nM. In the rest of the paper, kinase and phosphatase will refer to the active kinase and the active phosphatase. We assume that the cell chamber is homogeneous at the cross section, thus, we only considered one space dimension, $x$, the distance from the left end point of the chamber. As indicated in Figure 1, $x$ varies from 0 to $\ell$, where 0 corresponds to the left end of the perifusion chamber and $\ell$ is the length of the chamber.

The system of partial differential equations on the domain $x \in[0, \ell]$ and $t \geq 0$ is:

$$
\begin{aligned}
F_{t}(x, t)+v F_{x}(x, t) & =-k_{1}(R(x, t)-B(x, t)) F(x, t)+k_{2} B(x, t) \\
B_{t}(x, t) & =k_{1}(R(x, t)-B(x, t)) F(x, t)-k_{2} B(x, t) \\
R_{t}(x, t) & =a_{0}-b_{0} R(x, t)-c_{0} B(x, t) \\
K_{t}(x, t) & =b_{1} B(x, t)-a_{1} K(x, t) P(x, t) \\
P_{t}(x, t) & =b_{2} K(x, t)-a_{2} P(x, t) \\
L_{t}(x, t)+v L_{x}(x, t) & =b s+b_{3} K(x, t)
\end{aligned}
$$

with initial conditions:

$$
\begin{aligned}
& F(x, 0)=B(x, 0)=K(x, 0)=P(x, 0)=L(x, 0)=0 \\
& R(x, 0)=R_{\text {in }}, \text { for } 0<x \leq \ell
\end{aligned}
$$

and boundary conditions:

$$
\begin{aligned}
& L(0, t)=0 \\
& F(0, t)=f(t)
\end{aligned}
$$


The meaning of parameters is given in Table 1. Equation (1a) describes the evolution of the free GnRH. The advection term $v F_{x}(x, t)$ models the movement of the free GnRH down the chamber. The right hand sides of the equations (1a) and (1b) describe the binding and dissociation of $\mathrm{GnRH}$ to and from its receptor. The term $R(x, t)-B(x, t)$ gives the concentration of the free receptors to which free GnRH can bind. Unlike (1a), the equation (1b) does not have an advection term, since, once GnRH is bound to its receptor, it cannot move. Similarly, the equations for the total receptors (1c), the kinase (1d) and the phosphatase (1e) do not have the advection term, since they are associated with the cells and their positions in the cell chamber do not change. The receptors are produced with rate $a_{0}$ and are removed from the cell membrane with rate $b_{0}$, which describe the GnRH independent receptor dynamics. Bound GnRH leads to desensitization of the GnRH receptors, as described by the term $-c_{0} B(x, t)$ in the equation (1c), forming a negative feedback loop. The kinases are activated by the bound $\mathrm{GnRH}$ and inactivated by phosphatases represented by the $b_{1} B(x, t)$ and $-a_{1} K(x, t) P(x, t)$ terms in the equation (1d). The phosphatases are activated by kinases, and they are deactivated with rate $a_{2}$ as given in the equation (1e). The equation describing the concentration of the LH (1f) has an advection term, $v L_{x}(x, t)$, because secreted LH moves down the cell chamber with the fluid. LH has two source terms: $b s$ models the GnRH independent basal LH secretion and the $b_{3} K(x, t)$ term models GnRH dependent secretion, where activation of the kinases lead to LH secretion. We assume that the secretion is instantaneous.

The parameter $b s$ can be calculated from the GnRH independent steady state basal LH level at $x=\ell$, which is achieved before $\mathrm{GnRH}$ introduction to the chamber in the experiments. When the steady state is achieved, $L_{t}(x, t)$ term will be zero in the equation (1f). Since the basal LH secretion is independent of GnRH stimulation, $K(x, t)$ term will be zero too. So the steady state basal LH will satisfy $v L_{x}(x, t)=b s$. At $x=\ell$, the steady state basal LH is equal to $(b s \times \ell) / v$.

Initially there are no GnRH, kinase, phosphatase or LH in the chamber and the initial total receptor concentration, $R_{i n}$, is assumed to be the same at every point, as given by the initial conditions (2). We assume that the cells have constant density on the interval $(0, \ell]$. Thus, there is no production of LH at $x=0$, as given by the boundary condition (3a). We model the free GnRH input into the chamber as a boundary condition. If $A \mathrm{nM}$ of $\mathrm{GnRH}$ is introduced into the chamber for $\tau$ minutes, then in the equation (3b), $f(t)=A$ for $0 \leq t \leq \tau$ and $f(t)=0$ otherwise. In perifusion experiments the $\mathrm{GnRH}$ is given as a single pulse or as a train of pulses. To model the latter case, we incorporate the period of the pulses into the boundary condition.

We ignore diffusion, since we assume that the advection is the predominant way of mass transport in the systems discussed in this paper based on the following argument: The Peclet $(\mathrm{Pe})$ number, $P e=(v \ell) / D$, gives the ratio of mass transport through advection and through diffusion [29]. $v$ is the velocity of the 
Table 1: Parameters in the Model

\begin{tabular}{llll}
\hline$v$ & flow velocity of the culture medium & $a_{1}$ & deactivation rate of kinase \\
$\ell$ & length of the cell chamber & $b_{2}$ & activation rate of phosphatase \\
$k_{1}$ & binding rate of free GnRH & $a_{2}$ & deactivation rate of phosphatase \\
$k_{2}$ & dissociation rate of bound GnRH & $b s$ & basal LH secretion rate \\
$a_{0}$ & synthesis rate of GnRH-R & $R_{i n}$ & initial GnRH-R concentration \\
$b_{0}$ & internalization rate of GnRH-R & $b_{3}$ & LH secretion rate \\
$c_{0}$ & desensitization rate of GnRH-R & $A$ & delivered free GnRH concentration \\
$b_{1}$ & activation rate of kinase & period & period of pulses \\
$\tau$ & pulse duration & & \\
\hline
\end{tabular}

fluid flow, $\ell$ is the length along which the mass transfer happens and $D$ is the diffusion coefficient of the transported substance. The Pe number of the perifusion system discussed in Section 3.1.1 is approximately 3700 for GnRH and 19000 for LH, because the velocity is $0.2 \mathrm{~mm} / \mathrm{sec}, \ell$ is $5.56 \mathrm{~mm}$, the diffusion coefficient of $\mathrm{GnRH}$ is $3.04 \times 10^{-6} \mathrm{~cm}^{2} / \mathrm{sec}$ [30] and the diffusion coefficient of LH is $6 \times 10^{-7} \mathrm{~cm}^{2} / \mathrm{sec}[31]$. Since the Pe numbers are $>>1$ for the transported substances, advection dominates diffusion in this system.

\section{RESULTS}

\subsection{Perifusion Experiments}

\subsubsection{Triphasic Response}

Cantor et al. [26] developed a microperifusion system for monitoring LH release from gonadotrophs using adult female sheep anterior pituitary fragments. The medium coming from the cell chamber was collected at 30-second intervals and the LH content of these fractions was determined. The cells in the perifusion chamber secreted a basal level of LH before the introduction of GnRH. The GnRH dependent LH response at $x=\ell$ had three phases. Upon introduction of $\mathrm{GnRH}$ there was a rapid response forming an initial peak, which was followed by a lower steady state level of LH during the GnRH stimulation. Finally, upon cessation of the GnRH stimulation LH slowly returned to the basal level.

Model Simulation, The LH concentrations of 30-second collections are shown in Figure 4, Panel A, where the red dots are the data points taken from [26]. The black points and the black line connecting them are the simulation results. The time required for the simulation to reach the steady state basal LH level is not shown. The GnRH input, which is represented by the black line at the top, is given to the chamber for 240 seconds. Other panels in Figure 4 show simulation results for the time courses of kinase, phosphatase, bound GnRH 

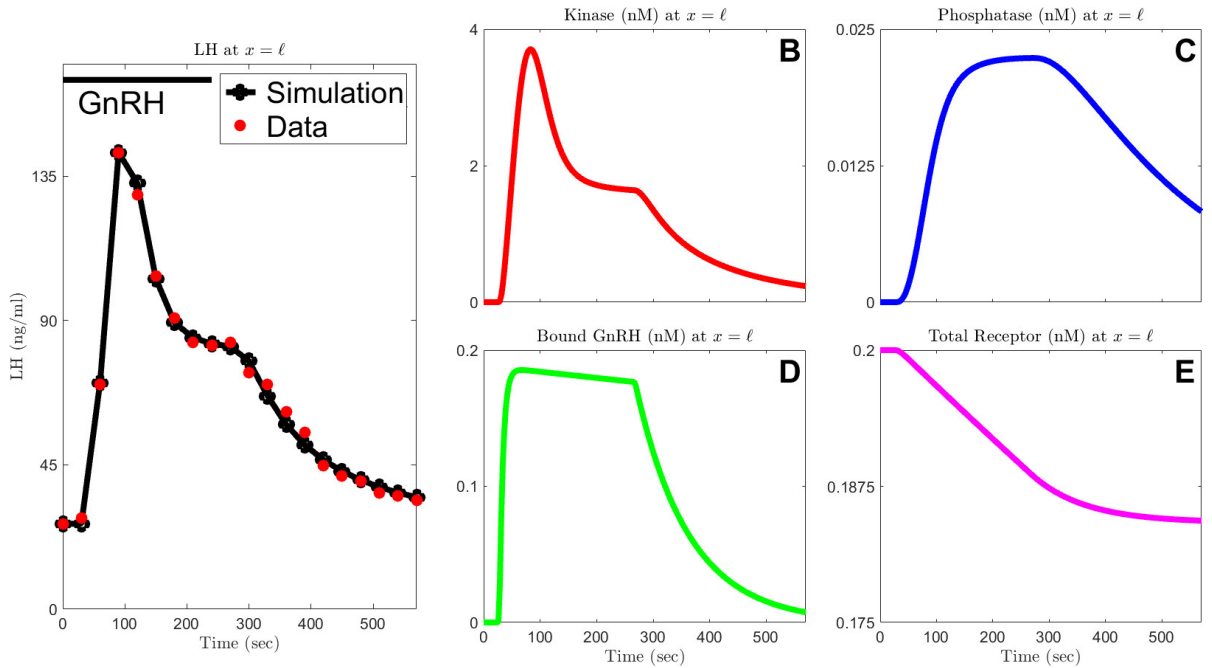

Figure 4: Time Course of Species at $x=\ell$. Panel A shows the amount of LH collected in 30 -second fractions in $\mathrm{ng} / \mathrm{ml}$. The red dots are the data points, whereas the black dots and the black line connecting them are the simulation results. The 240 second GnRH stimulation is indicated at the top of the graph with the black line. Panels B, C, D and E show the simulation result for the time courses of kinase, phosphatase, bound GnRH and total receptor concentrations at $x=\ell$ in nM. All simulations last 570 seconds. Note that the scales are different in each panel.

and total receptor concentrations at $x=\ell$ for $570 \mathrm{sec}$. When interpreting these graphs, keep in mind that the LH profile in Panel A is the result of the collective action of all kinases at all locations in the chamber.

In Panel A, as seen in the first two red dots, the LH content in the first two collections are equal, since the LH secreted at the left end of the cell chamber takes time to travel down to the right end of the chamber. More specifically, since the length of the column is $5.56 \mathrm{~mm}$ and the flow velocity of the medium is $0.2 \mathrm{~mm} / \mathrm{sec}$, the passage time for LH is 27.8 seconds. Similarly, in the other panels in Figure 4, the concentrations at $x=\ell$ do not rise in the first approximately 30 seconds until the free GnRH reaches $x=\ell$ and initiates the activation of the signaling cascade at that point. With the parameters used in this simulation free GnRH also moves with velocity $0.2 \mathrm{~mm} / \mathrm{sec}$, however with different parameters it can have a different velocity. For a detailed discussion of the movement of GnRH see Section 3.2.2. After this initial flat line in the LH content of the first two collections, we see a rapid increase in the LH content of fractions, which constitutes the first part of the characteristic triphasic response. Likewise, kinase (Panel B), phosphatase (Panel C) and bound GnRH (Panel D) concentrations rapidly increase following the initial flat line. This rapid initial increase of kinases in the chamber leads to the initial rise in the LH secretion. 
After achieving its peak value, the LH content of the collections decreases to a lower plateau and remains steady until about 30 seconds after the end of the GnRH introduction into the chamber. This approximate 30 seconds delay is the time required for the last part of the $\mathrm{GnRH}$ signal introduced at the left end point of the chamber to reach the right end point. This steady LH level originates from the quasi steady state levels reached by the kinase, phosphatase and bound GnRH in this time period. The steady level of the bound GnRH decreases slightly, as the total receptor concentration at $x=\ell$ also slightly decreases due to the receptor desensitization.

After this quasi steady-state level, the LH concentration decreases gradually back to the basal LH secretion level (Panel A), forming the last phase of the triphasic response. Upon cessation of the $\mathrm{GnRH}$ introduction into the chamber, the bound GnRH levels start to drop. Bound GnRH at $x=\ell$ decreases after about 270 seconds, where 240 seconds is the length of GnRH stimulation and 30 seconds is approximately the passage time through the chamber. The decrease in bound GnRH leads to a decrease in the kinase (Panel B) and in turn in the LH levels (Panel A). The rate by which LH returns to the basal level is primarily determined by the dissociation constant of bound $\mathrm{GnRH}, k_{2}$.

The total receptor concentration changes only slightly during the simulation, since the $c_{0}$ term is small to have a significant affect in 570 seconds. Thus, for this data set the total receptor dynamics does not affect the LH profile. Receptor desensitization is more prominent with multiple pulses over a longer time period, as we will see in the next section.

Determination of Model Parameters, The details of the experimental setup are explained in [26, 32]. The volume of the cell chamber is $32 \mu \mathrm{l}$, with a $2.69 \mathrm{~mm}$ diameter and a $5.563 \mathrm{~mm}$ height. Thus, the cross sectional area of the cell chamber is $5.6832 \mathrm{~mm}^{2}$. The flow rate of the culture medium is 72 $\mu \mathrm{l} / \mathrm{min}$. Thus, the one-dimensional velocity, $v$, is $0.2 \mathrm{~mm} / \mathrm{sec}$. The stimulation time of GnRH, $\tau$, is 240 seconds. The cells are mixed with beads before loading. The beads occupy $17 \mu \mathrm{l}$, whereas the cells and the fluid occupy $15 \mu \mathrm{l}$. Approximately $2 \times 10^{5}$ cells are loaded into the chamber. We assume there are

\begin{tabular}{lcl}
\multicolumn{3}{c}{ Table 2: Parameters for Section 3.1.1 } \\
\hline$v=0.2 \mathrm{~mm} / \mathrm{sec}$ & $k_{1}=0.0091 / \mathrm{nM} \cdot \mathrm{sec}$ & $a_{1}=2.9348 / \mathrm{nM} \cdot \mathrm{sec}$ \\
$A=17 \mathrm{nM}$ & $k_{2}=0.0108 / \mathrm{sec}$ & $b_{2}=0.0001 / \mathrm{sec}$ \\
$\tau=240 \mathrm{sec}$ & $a_{0}=0.000001 \mathrm{nM} / \mathrm{sec}$ & $a_{2}=0.0073 / \mathrm{sec}$ \\
$R_{\text {in }}=0.2 \mathrm{nM}$ & $b_{0}=a_{0} / R_{\text {in }} / \mathrm{sec}$ & $b_{3}=0.0402 / \mathrm{sec}$ \\
$b s=0.0319 \mathrm{nM} / \mathrm{sec}$ & $c_{0}=0.0002678 / \mathrm{sec}$ & $\Delta t=0.01 \mathrm{sec}$ \\
$\ell=5.56 \mathrm{~mm}$ & $b_{1}=0.6058 / \mathrm{sec}$ & $\Delta x=0.01 \mathrm{~mm}$ \\
\hline
\end{tabular}


$10^{4} \mathrm{GnRH}$ receptors per cell [21], thus, the initial total GnRH-R concentration is $R_{i n}=0.2 \mathrm{nM}$. The concentration of the $\mathrm{GnRH}$ given is $20 \mathrm{ng} / \mathrm{ml}$. Assuming the molecular weight of GnRH is $1,183.27$ Daltons, $1 \mathrm{ng} / \mathrm{ml} \mathrm{GnRH}=0.84 \mathrm{nM}$ GnRH. So, the amplitude of the free $\mathrm{GnRH}$ is $A=17 \mathrm{nM}$ in the simulation. The basal LH level is $26.6 \mathrm{ng} / \mathrm{ml}$ in the data, which is $26.6 / 30 \mathrm{nM} \mathrm{LH}$, given the molecular weight of LH is 30,000 Daltons. So, $b s=0.0319 \mathrm{nM} / \mathrm{sec}$. The mathematical model gives $\mathrm{LH}$ in $\mathrm{nM}$, however the data is given in $\mathrm{ng} / \mathrm{ml}$. Thus, we convert $\mathrm{nM} \mathrm{LH}$ to $\mathrm{ng} / \mathrm{ml} \mathrm{LH}$ by multiplying the former by 30 . The data is the average LH in 30-second fractions, thus we calculate the average LH over 30 -second intervals and each average corresponds to a black dot in Figure 4 Panel A. The simulations run for 570 sec.

We determine the other parameters to match the simulation to the experimental data using an educated initial guess and minimizing the squares of errors using built-in MATLAB fminsearch function. The parameters $a_{0}$ and $b_{0}$ are chosen to have a constant total receptor concentration in the absence of $\mathrm{GnRH}$.

\subsubsection{Trains of Pulses}

McIntosh et al. [27] studied the secretion of LH in response to multiple GnRH pulses with varying pulse durations and periods using a perifusion system and female sheep pituitary cells. They gave multiple pulses and collected the outgoing medium in 6 minute intervals. Note that in Section 3.1.1 the time is in seconds, whereas in this section it is in minutes. Since the McIntosh data is not as finely sampled as the previous data, they did not observe the triphasic response. Thus, the effect of phosphatase based negative feedback is not seen in this data. However, the phosphatase effect is observed in the simulations when LH at a fixed point is plotted as a time course (the quasi steady state in Figure 7 Panel A) instead of ng/fraction (Figure 7 Panel B).

Model Simulation, Figure 5 shows the response of the gonadotroph cells to a variety of GnRH stimulation patterns. Panel A shows the simulation results and Panel B shows the data. The amount of LH in each fraction is marked as a line over the time interval the fraction is collected. In the data open rectangles are LH, whereas filled rectangles are FSH. We are only interested in the LH secretion in this work. The black bars at the top of the data show GnRH stimulation patterns. In Panel B, as in Panel A, each of the y-axes goes from 0 to 300 . Notice that in all these cases the simulation outcomes are very similar to the experimental results.

In Figure 5, the first row shows continuous GnRH stimulation. In the following rows, $\mathrm{GnRH}$ is given for 5 minutes every 10 minutes, every 40 minutes and every 60 minutes. Continuous stimulation (first row) and five-minute pulses every 10 minutes (second row) eventually suppress the secretion of LH both in the simulation and in the data. In the other two cases, the peaks decrease in height gradually with consequent pulses. The LH response diminishes due to 


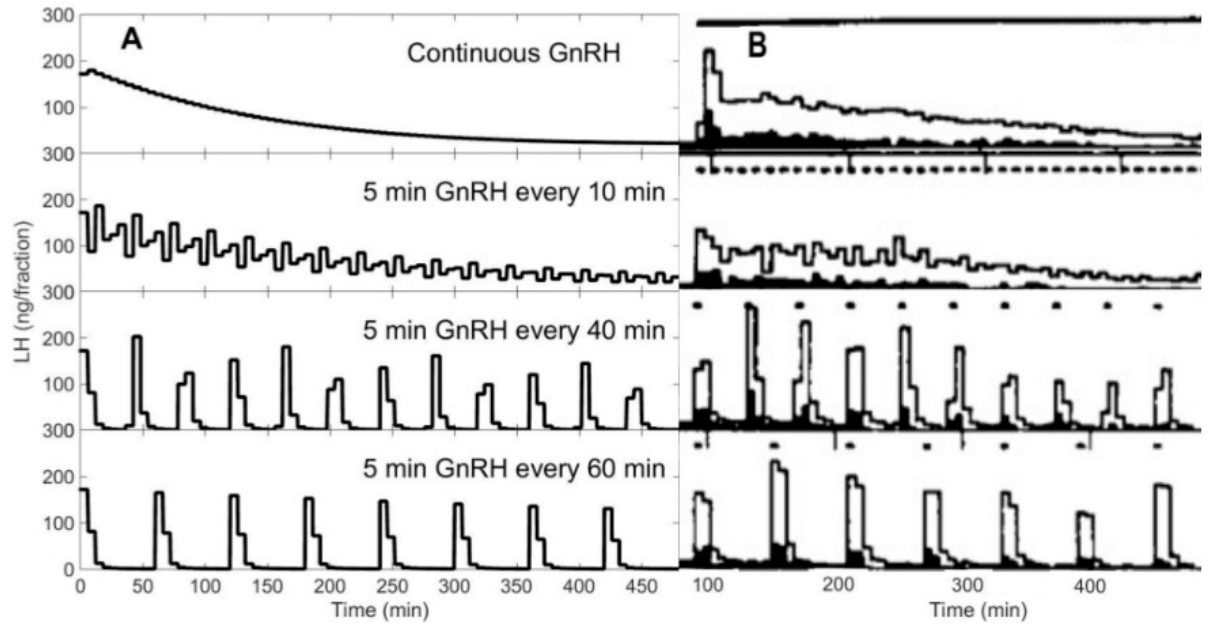

Figure 5: LH secretion patterns. Panel A shows the simulation results; Panel B shows the corresponding data. The black lines at the top of the data show GnRH stimulation pattern, which are written at the right top corner of the simulation results. First row demonstrates continuous GnRH stimulation, the second row 5 minute GnRH pulses every 10 minutes, the third row 5 minute GnRH every 40 minutes and the last row shows 5 minute GnRH pulses every 60 minutes. The simulations run for 480 minutes and the medium coming from the cell chamber is collected for 6 minutes. For the graphs on Panel B, the black lines representing GnRH stimulation patterns are at the level of $300 \mathrm{ng} /$ fraction on the y-axis. The data is modified from [27].

the receptor desensitization, which is represented by the $c_{0} B(x, t)$ term in the equation (1c). Figure 6 presents total receptor and bound GnRH concentrations at $x=\ell$ for the four different cases. With every pulse, the bound GnRH leads to a decrease in the total receptor concentration. In the continuous and high frequency stimulations, the total receptor concentrations decrease rapidly as seen by the black and blue curves in Panel A. However, in the other two cases, fewer pulses are given, and thus the total receptor concentration decreases more slowly as seen in the red and green curves. The decline in total receptor concentration decreases the bound GnRH concentration with subsequent pulses as represented in panels $\mathrm{B}, \mathrm{C}, \mathrm{D}$ and $\mathrm{E}$.

Importance of the Fraction Collection Time, The simulations of LH at $x=\ell$ generate a continuous and periodic LH pattern with the same shaped response for every pulse, yet, with decreasing heights due to the receptor desensitization. However, integrating this regular LH output over a fraction collection time which does not divide the period of the simulations evenly leads to an irregularly shaped LH outcome with varying heights as in Figure 5, third row of Panel A, where 5 minute GnRH pulses are introduced every 40 minutes and the medium is collected in 6 minute fractions. The LH output for this case has three different shapes (compare the second, third and fourth pulses) with different heights repeated for the rest of the simulation. This pattern looks like an 

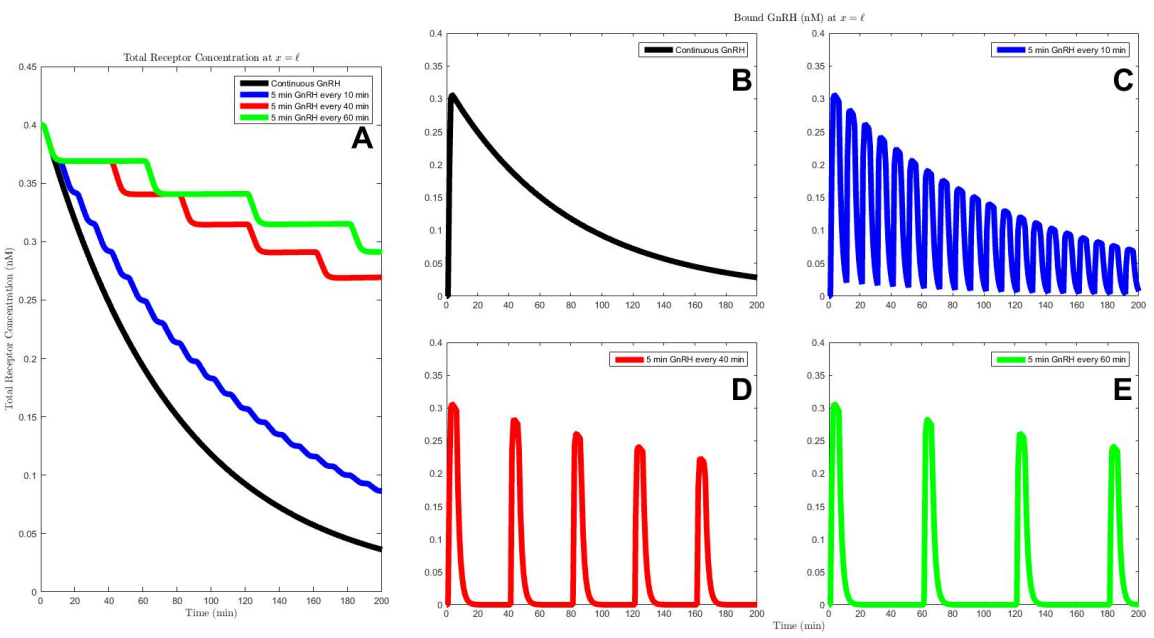

Figure 6: Simulations of Total Receptor and Bound GnRH Time Courses at $x=\ell$ with varying GnRH Stimulation Frequencies. The total receptor concentrations at $x=\ell$ with four different $\mathrm{GnRH}$ stimulation frequencies are given in Panel A: continuous GnRH stimulation (black); 5 min every 10 min (blue); 5 min every 40 min (red); 5 min every $60 \mathrm{~min}$ (green). Other panels show the bound GnRH time course at $x=\ell$ for each specific GnRH stimulation pattern.

interesting biological phenomenon, however, this irregularity in the simulation is only an artifact of the fraction collection time. Unlike 40-minute stimulation period, the stimulation with period 60 minutes has the same shape repeated (Figure 5, fourth row), since 6 minute fraction collection time divides 60 minute period evenly. The influence of fraction collection time can be seen more clearly in Figure 7, where LH in nM (Panel A) and LH in ng/fraction (Panel B) are shown side by side. Thus, the fraction collection time determines the regularity and the height of the LH output.

The difference in the first two LH peaks of the data of 40 minute pulse period (Panel B, third row) is partly due to the way the medium is collected, but also self-priming might play a role (See Discussion).

Table 3: Parameters for Section 3.1.2

\begin{tabular}{lll} 
& \multicolumn{2}{c}{ Table 3: Parameters for Section 3.1.2 } \\
\hline$v=7 \mathrm{~mm} / \mathrm{min}$ & $k_{1}=60 \times 0.0091 / \mathrm{nM} \cdot \min$ & $a_{1}=60 \times 2.9348 / \mathrm{nM} \cdot \min$ \\
$A=4.23 \mathrm{nM}$ & $k_{2}=60 \times 0.0108 / \mathrm{min}$ & $b_{2}=60 \times 0.0001 / \mathrm{min}$ \\
$\tau=$ varying & $a_{0}=60 \times 0.000001 \mathrm{nM} / \mathrm{min}$ & $a_{2}=60 \times 0.0073 / \mathrm{min}$ \\
$R_{\text {in }}=0.4 \mathrm{nM}$ & $b_{0}=a_{0} / R_{\text {in }} / \mathrm{min}$ & $b_{3}=60 \times 0.0402 / \mathrm{min}$ \\
$b s=0 \mathrm{nM} / \mathrm{min}$ & $c_{0}=60 \times 0.0002678 / \mathrm{min}$ & $\Delta t=0.001 \mathrm{~min}$ \\
$\ell=10 \mathrm{~mm}$ & $b_{1}=60 \times 0.6058 / \mathrm{min}$ & $\Delta x=0.01 \mathrm{~mm}$ \\
\hline
\end{tabular}



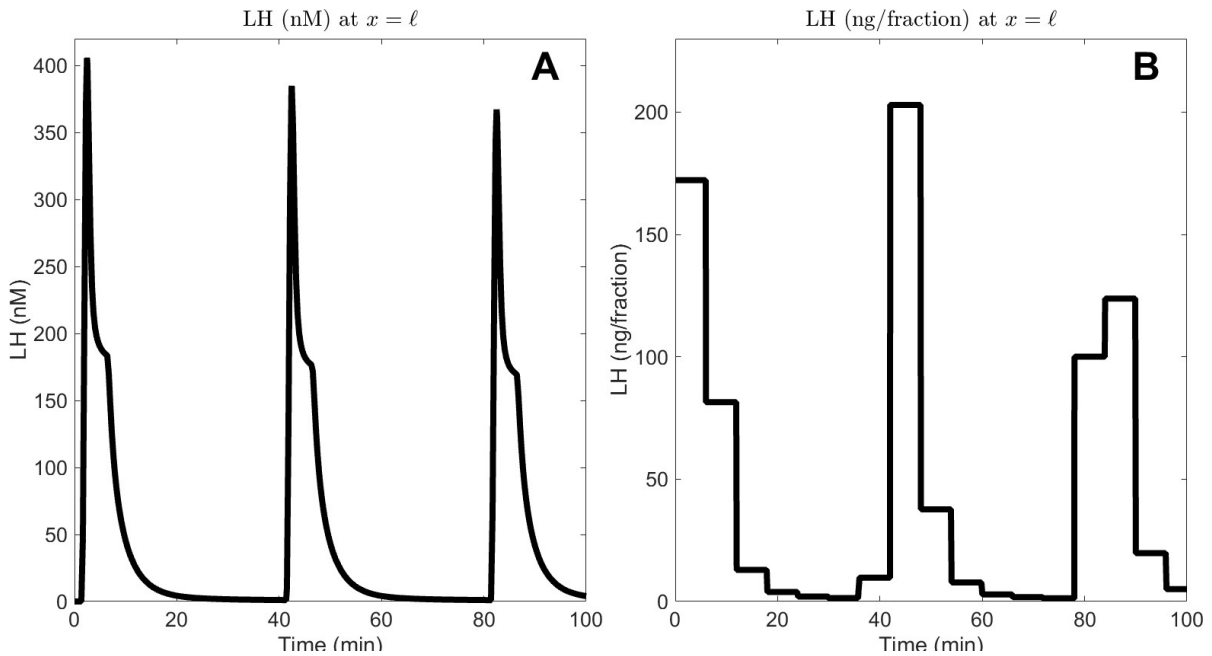

Figure 7: Simulations of the LH at $x=\ell$. Panel A shows LH time course at $x=\ell$ in $\mathrm{nM}$. The triphasic response, which is not captured in the data, can be seen in the simulation in Panel A. Panel B shows LH in ng/fraction. The graph in Panel A is averaged over 6 minute intervals and $\mathrm{nM}$ is converted into $\mathrm{ng}$ to calculate $\mathrm{ng} /$ fraction, which is presented in panel B. The graph in Panel B is the simulation from Panel A collected in 6 minute fractions and changed into ng/fraction. When this is done, the quasi steady states from Panel A are obscured.

Determination of Model Parameters, The flow rate is $0.14 \mathrm{ml} / \mathrm{min}$. Approximately $5 \times 10^{6}$ cells are loaded to the cell chambers. GnRH concentration is $4.23 \mathrm{nM}$. They use $1 \mathrm{ml}$ syringe barrels as the cell chamber [33, 34]. Although they don't give the cross sectional area of the particular syringe they used, we assume it is about $20 \mathrm{~mm}^{2}$ based on the average $1 \mathrm{ml}$ syringe dimensions. Thus, the one-dimensional velocity, $v$, is $7 \mathrm{~mm} / \mathrm{min}$. In the diagrammatic description of the perifusion apparatus in [34] the volume of the column contents is given as $0.4 \mathrm{ml}$, where $0.2 \mathrm{ml}$ of it is occupied by the packing material, leaving the cells $0.2 \mathrm{ml}$. So, the height of the volume that the cells cover is $10 \mathrm{~mm}$. We take $b s=0$, because the basal level is indistinguishable in this data set. They collect 6-minute fractions, and give their results as ng/fraction. We change $\mathrm{nM}$ to $\mathrm{ng} / \mathrm{ml}$ by multiplying LH by 30 and change $\mathrm{ng} / \mathrm{ml}$ to $\mathrm{ng} /$ fraction by further multiplying the result by 0.84 . Finally, we take the average of LH over 6 minute time periods. Unlike the previous part, the averages are not given as dots, but presented as bars over the time period the average is taken.

This data set serves as a cross validation of the parameters used in Section 3.1.1. We use the same physiological parameters multiplied by 60 to convert $/ \mathrm{sec}$ to $/ \mathrm{min}$. 


\subsubsection{Oxytocin vs $G n R H$}

Gonzales-Iglesias et al. [28] compared the effects of oxytocin and GnRH on adult female Sprague Dawley rat pituitary cells. Both hormones lead to secretion of LH, though with different dynamics.

Simulation Results, Figure 8 shows the LH response to 7 minutes $5 \mathrm{nM}$ GnRH stimulation in Panel A and to 10 minute $10 \mathrm{nM}$ oxytocin stimulation in panels B and C. The red dots are the data points taken from [28], whereas the black dots and the black lines connecting them are simulation results. Oxytocin stimulation leads to a lower level of LH secretion compared to GnRH stimulation.

In all the graphs there is no difference in the LH content of the first two fractions, since the passage time through the chamber is one minute, given that the velocity is $3.8 \mathrm{~mm} / \mathrm{min}$ and the chamber length is $3.8 \mathrm{~mm}$.

We match the parameters to reproduce the GnRH data and then recover oxytocin data by changing only the parameters related to the receptor dynamics. The strength of the receptor desensitization is controlled by the parameter $c_{0}$ as represented in the equation (1c). Since the oxytocin receptor desensitizes faster than the GnRH-R, $c_{0}$ term for the oxytocin receptor should be larger (see Discussion). In Figure 8 Panel B, all the parameters, except $c_{0}$, are the same as the ones used for Panel A. Also, the densities of the GnRH and oxytocin receptors might be different on the cell membrane. In Panel C, all the parameters, except $c_{0}$ and $R_{i n}$, are the same as the ones used for Panel A. By changing two parameters instead of one, the fit of the simulation to data is improved. The receptor desensitization and/or the difference in the receptor concentration on the cell membrane can explain the difference in the action of these two hormones.

Determination of Model Parameters, Approximately $4 \times 10^{6}$ cells were put into $0.5 \mathrm{ml}$ chambers with $13 \mathrm{~mm}$ diameter (personal communication). Thus $\ell$ is approximately $3.8 \mathrm{~mm}$. They give $5 \mathrm{nM}$ GnRH for 7 minutes and $10 \mathrm{nM}$ oxytocin for 10 minutes. They collect the medium at 1-minute intervals. Flow rate of the culture medium is $0.5 \mathrm{ml} / \mathrm{min}$, thus one-dimensional velocity is 3.8 $\mathrm{mm} / \mathrm{min}$. Assuming that there are about $10^{4} \mathrm{GnRH}$ receptors per cell [21], the concentration of $\mathrm{GnRH}$ receptors in the cell chamber is approximately $0.13 \mathrm{nM}$. The results are given in $\mathrm{ng} / \mathrm{min}$. In $1 \mathrm{~min}$ they collect $0.5 \mathrm{ml}$, so we multiply $\mathrm{LH}$ first by 30 to convert $\mathrm{nM}$ to $\mathrm{ng} / \mathrm{ml}$, then by 0.5 to convert $\mathrm{ng} / \mathrm{ml}$ to $\mathrm{ng} / \mathrm{min}$. The parameter $b s$ is calculated using the first point in the data sets, which are $0.3871 \mathrm{ng} / \mathrm{min}$ for $\mathrm{GnRH}$ stimulation data and $0.2581 \mathrm{ng} / \mathrm{min}$ for oxytocin stimulation data, which correspond to $b s=0.0258 \mathrm{nM} / \mathrm{min}$ and $b s=0.0172$ $\mathrm{nM} / \mathrm{min}$ respectively. The rest of the parameters are determined to match the data as in the previous sections.

To reproduce the difference in GnRH and oxytocin stimulated LH release, 


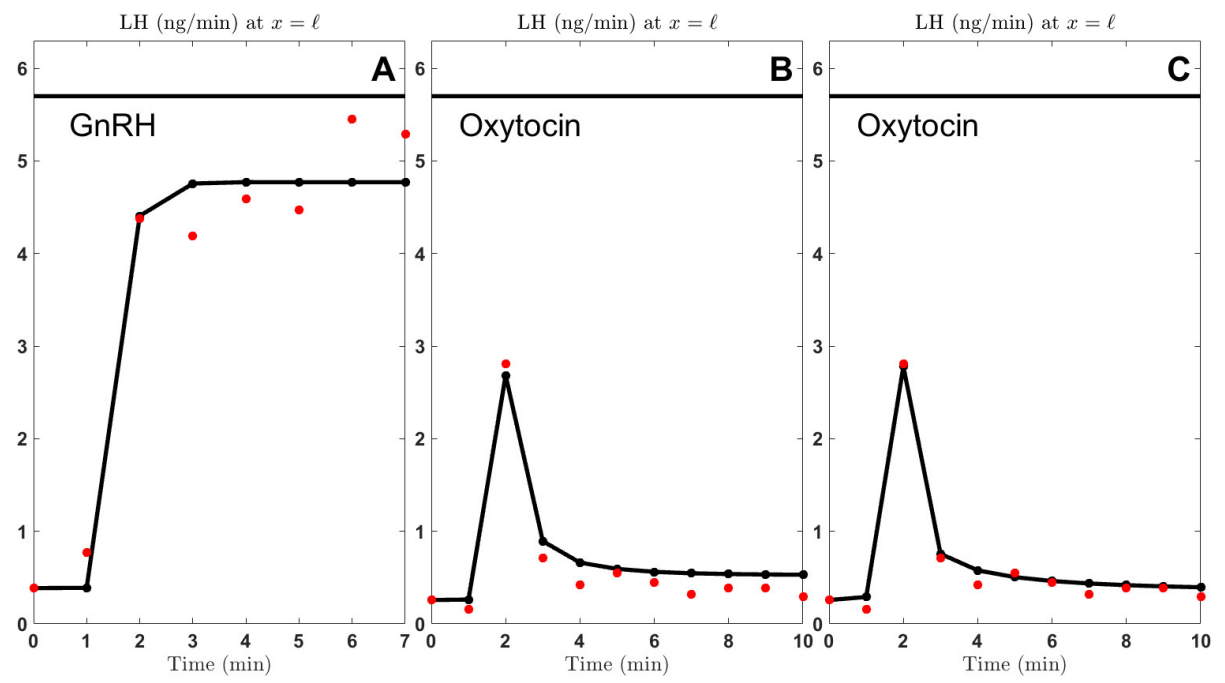

Figure 8: LH Response to GnRH and Oxytocin. The red points are the data taken from [28]; the black dots and lines are the simulation results. Panel A shows LH secretion in response to 7 minutes $5 \mathrm{nM}$ GnRH stimulation. Panels $\mathrm{B}$ and $\mathrm{C}$ show the $\mathrm{LH}$ response to 10 minutes $10 \mathrm{nM}$ oxytocin stimulation. In Panel $\mathrm{B}$ only the parameter $c_{0}$ is different from the parameters used for GnRH stimulation (Panel A), whereas in Panel C both $c_{0}$ and initial total receptor concentration are different.

first we only changed the $c_{0}$ parameter from $0.0000916 / \mathrm{min}$ to $232 / \mathrm{min}$ in Figure 8 Panel B. In Panel $\mathrm{C}$ we change both $c_{0}$ and $R_{i n}$ : we change $c_{0}$ from $0.0000916 / \mathrm{min}$ to 1550 and $R_{\text {in }}$ from $0.13 \mathrm{nM}$ to $0.95 \mathrm{nM}$. Why should $c_{0}$ be so low for GnRH-R and much higher for the oxytocin receptor? Both are G-protein coupled receptors $[17,41]$. There is some evidence that the $c_{0}$ for GnRH-R should be very small, because GnRH-R desensitizes unusually slowly compared to other G-protein coupled receptors. $\left[{ }^{3} \mathrm{H}\right]$ inositol phosphate accumulation, an indicator of receptor activation, was maintained for at least 90 minutes with GnRH-R as opposed to the typical 1 minute with desensitizing receptors [17].

Table 4: Parameters for GnRH Stimulation in Section 3.1.3

\begin{tabular}{lll}
\hline$v=3.8 \mathrm{~mm} / \mathrm{min}$ & $k_{1}=0.072 / \mathrm{nM} \cdot \min$ & $a_{1}=1866 / \mathrm{nM} \cdot \mathrm{min}$ \\
$A=5 \mathrm{nM}$ & $k_{2}=27.213 / \mathrm{min}$ & $b_{2}=0.0187 / \mathrm{min}$ \\
$\tau=7 \mathrm{~min}$ & $a_{0}=0.001494 \mathrm{nM} / \mathrm{min}$ & $a_{2}=4.3148 / \mathrm{min}$ \\
$R_{\text {in }}=0.13 \mathrm{nM}$ & $b_{0}=a_{0} / R_{\text {in }} / \mathrm{min}$ & $b_{3}=0.5449 / \mathrm{min}$ \\
$b s=0.0258 \mathrm{nM} / \mathrm{min}$ & $c_{0}=0.0000916 / \mathrm{min}$ & $\Delta t=0.001 \mathrm{~min}$ \\
$\ell=3.8 \mathrm{~mm}$ & $b_{1}=1368 / \mathrm{min}$ & $\Delta x=0.01 \mathrm{~mm}$
\end{tabular}


LH at $x=\ell$ with Varying Velocities

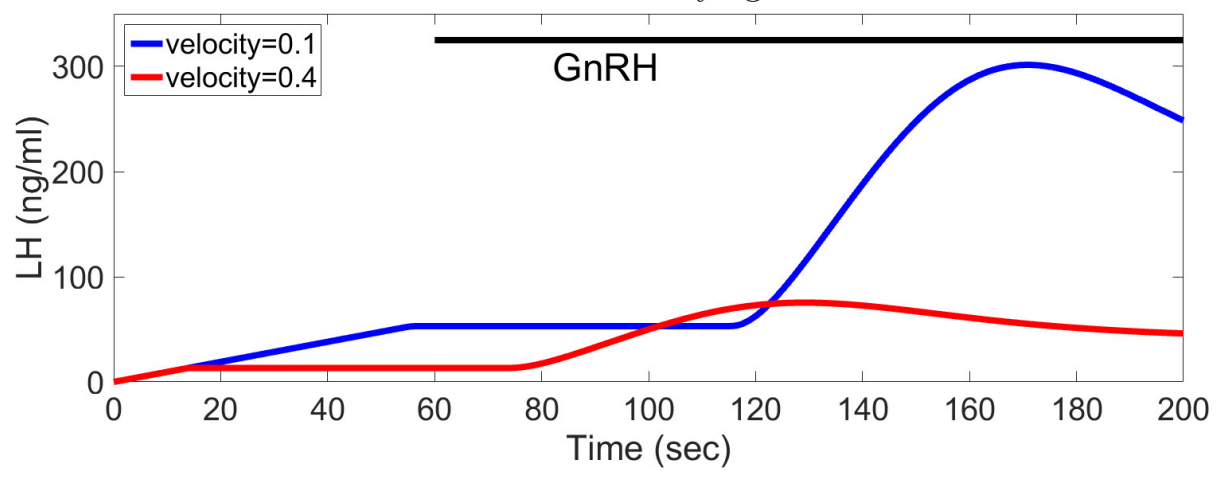

Figure 9: Dependence of LH at $x=\ell$ on the flow velocity of the culture medium. The blue line shows the simulation with flow velocity $0.1 \mathrm{~mm} / \mathrm{sec}$ and the red line with velocity $0.4 \mathrm{~mm} / \mathrm{sec} .17 \mathrm{nM} \mathrm{GnRH}$ is supplied to the cell chamber starting at the 60th second for the rest of the simulation, represented by the black line at the top.

\subsection{In silico experiments}

\subsubsection{Dependence of Data on the Flow Rate of the Culture Medium}

To examine the influence of the flow rate of the culture medium on the outcome of the perifusion experiments, we use the parameters from Section 3.1.1 and vary the velocity, $v$. Figure 9 shows the LH at $x=\ell$ with two different velocities. The blue line shows the simulation with velocity $0.1 \mathrm{~mm} / \mathrm{sec}$ and the red line with velocity $0.4 \mathrm{~mm} / \mathrm{sec}$.

As explained in Section 2, the steady state basal LH level at $x=\ell$ is equal to $(b s \times \ell) / v$. Thus, small velocities lead to a higher steady state basal LH level, as shown in the Figure 9. Slow velocity (blue) has higher basal steady state LH level. More specifically, since $\ell=5.56 \mathrm{~mm}, v=0.1 \mathrm{~mm} / \mathrm{sec}, b s=0.0319$ $\mathrm{nM} / \mathrm{sec}$, the steady state basal LH level at $x=\ell$ is $53.2 \mathrm{ng} / \mathrm{ml}$. This steady state LH level is $13.3 \mathrm{ng} / \mathrm{ml}$ for the velocity $0.4 \mathrm{~mm} / \mathrm{sec}$ (red). Also, slow velocities take longer to reach this steady state basal LH level. The time required to reach this basal level is $\ell / v$, which is 55.6 seconds for velocity $0.1 \mathrm{~mm} / \mathrm{sec}$ and 13.9 seconds for the velocity $0.4 \mathrm{~mm} / \mathrm{sec}$.

In the simulations, the GnRH is supplied into the cell chamber starting at the $60^{\text {th }}$ second until the end of the simulation, as represented by the black line at the top of Figure 9. The LH levels at the right end point of the chamber start increasing after $\ell / v$ seconds passage time through the chamber. This passage time is 55.6 seconds when velocity is $0.1 \mathrm{~mm} / \mathrm{sec}$ and 13.9 seconds when the velocity is $0.4 \mathrm{~mm} / \mathrm{sec}$. When velocity is small, the quantity of the LH collected at the right end point of the chamber is greater, since with smaller velocities more LH accumulates in the chamber, before it is washed out. Thus, when the velocity is small, the LH appears later in the collections, however, in greater 


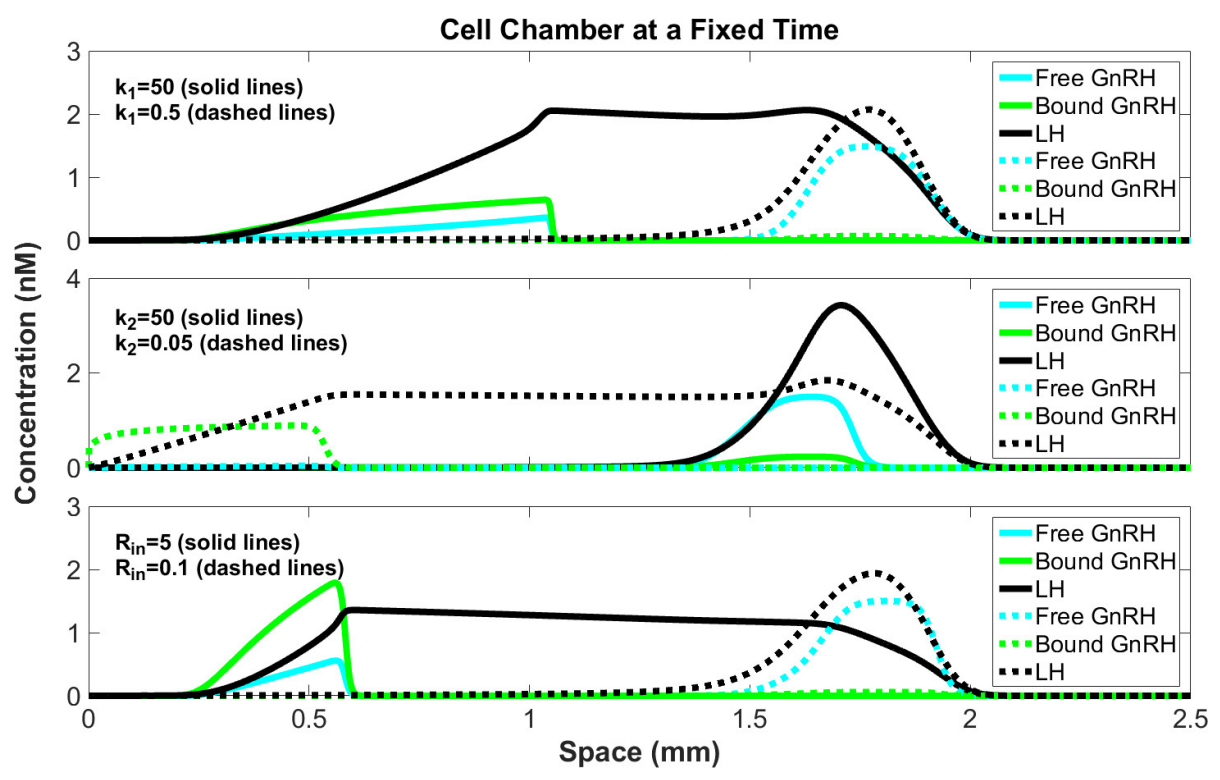

Figure 10: GnRH Movement in the Cell Chamber with Varying Parameters. The simulations show free GnRH (cyan lines), bound GnRH (green lines) and LH (black lines) concentrations at a fixed time in the cell chamber. In each row the solid lines and the dashed lines give the results of two simulations where all the parameters are the same except one key parameter, indicated in the upper left corner of the panels. In each panel, the parameters that are not being changed are given in Table 5 .

quantities.

\subsubsection{Movement of GnRH in the Cell Chamber}

In this section we give a qualitative description of how the GnRH movement down the chamber depends on the binding rate of free GnRH to the receptor, $k_{1}$; the dissociation rate of bound GnRH from the receptor, $k_{2}$, and the initial GnRH-R concentration, $R_{i n}$. Each row in Figure 10 shows two simulations (solid lines and dotted lines) in which only one parameter is changed. In the top row in both simulations, all parameters except $k_{1}$ are the same; in the middle row all parameters except $k_{2}$ are the same and in the bottom row all parameters except the initial receptor concentration $R_{i n}$ are the same. The black lines show $\mathrm{LH}$, the green lines show bound $\mathrm{GnRH}$ and the cyan lines show free $\mathrm{GnRH}$ in the chamber at $t=20$ seconds. The common parameters used in all simulations are given in Table 5. For each row in Figure 10, we take the parameters from that table, except one key parameter, and use for that parameter the values given on the top left corner of the panels.

The fronts of both the solid and the dashed black lines are at the same point in all simulations, since the movement of the LH down the chamber does not 
Table 5: Parameters for Section 3.2.2

\begin{tabular}{lll}
\hline$v=0.1 \mathrm{~mm} / \mathrm{min}$ & $k_{1}=10 / \mathrm{nM} \cdot \min$ & $a_{1}=10 / \mathrm{nM} \cdot \min$ \\
$A=1.5 \mathrm{nM}$ & $k_{2}=10 / \mathrm{min}$ & $b_{2}=0.4 / \mathrm{min}$ \\
$\tau=3 \mathrm{~min}$ & $a_{0}=0 \mathrm{nM} / \mathrm{min}$ & $a_{2}=0.5 / \mathrm{min}$ \\
$R_{\text {in }}=1 \mathrm{nM}$ & $b_{0}=a_{0} / R_{\text {in }} / \mathrm{min}$ & $b_{3}=0.5 / \mathrm{min}$ \\
$b s=0 \mathrm{nM} / \mathrm{min}$ & $c_{0}=0 / \mathrm{min}$ & $\Delta t=0.001 \mathrm{~min}$ \\
$\ell=2.5 \mathrm{~mm}$ & $b_{1}=3 / \mathrm{min}$ & $\Delta x=0.001 \mathrm{~mm}$ \\
fixed time $=20 \mathrm{~min}$ & & \\
\hline
\end{tabular}

depend on $k_{1}, k_{2}$ or $R_{i n}$. Once LH is secreted from the cells into the chamber, it moves with the velocity of the fluid flow, $v$. Also, in all simulations the profiles of the free and the bound GnRH are waves that move together.

The first row in Figure 10 shows the impact of $k_{1}$ on the GnRH movement. For this row $k_{2}=10 / \mathrm{min}$ and $R_{i n}=1 \mathrm{nM}$. The solid lines show the simulation with $k_{1}=50 / \mathrm{nM} \cdot \min$ and the dashed lines show the simulation with $k_{1}=0.5$ $/ \mathrm{nM} \cdot \min$. When $k_{1}$ is large (solid lines), the profiles of free and bound GnRH move more slowly and the bound GnRH level (green) is high. Thus, large $k_{1}$ leads to stronger activation of the signaling cascade, and eventually it leads to higher LH secretion. When comparing the total LH secreted, we compare the areas under the LH curves.

The middle row in Figure 10 illustrates the influence of $k_{2}$ on GnRH movement. For these simulations $k_{1}=10 / \mathrm{nM} \cdot \min ; k_{2}=50$ or $=0.05 / \mathrm{min}$ and $R_{i n}=1 \mathrm{nM}$. When $k_{2}$ is large (solid lines), the profiles of free and bound GnRH move faster. The rate of dissociation affects the tail of the GnRH bumps: if $k_{2}$ is high, the GnRH bumps are narrow (solid lines) and when $k_{2}$ is low, the bumps have longer tails (dashed lines). Thus, with small $k_{2}$ the bound GnRH dissociates more slowly, so the signaling cascade is activated for a longer time period. In our simulations with the particular choice of parameters, $k_{2}$ determines the rate at which LH at $x=\ell$ decreases to its basal level after the termination of free $\mathrm{GnRH}$ introduction into the chamber.

The bottom row in Figure 10 shows two simulations with different $R_{\text {in }}$ values, where $k_{1}=10 / \mathrm{nM} \cdot \min , k_{2}=10 / \mathrm{min}$ and $R_{\text {in }}=5$ or $0.1 \mathrm{nM}$. In this section the parameters $a_{0}, b_{0}$ and $c_{0}$ are zero, thus receptor concentrations are constant throughout the simulations. When receptor concentrations are high (solid lines), bound GnRH concentrations are high (green) and GnRH moves more slowly.

\subsubsection{Dependence of LH Secretion Efficiency on Pulse Characteristics}

To analyze further the effects of the pulse duration and the pulse period, McIntosh et al. [27] calculated the LH output per unit of GnRH introduced 


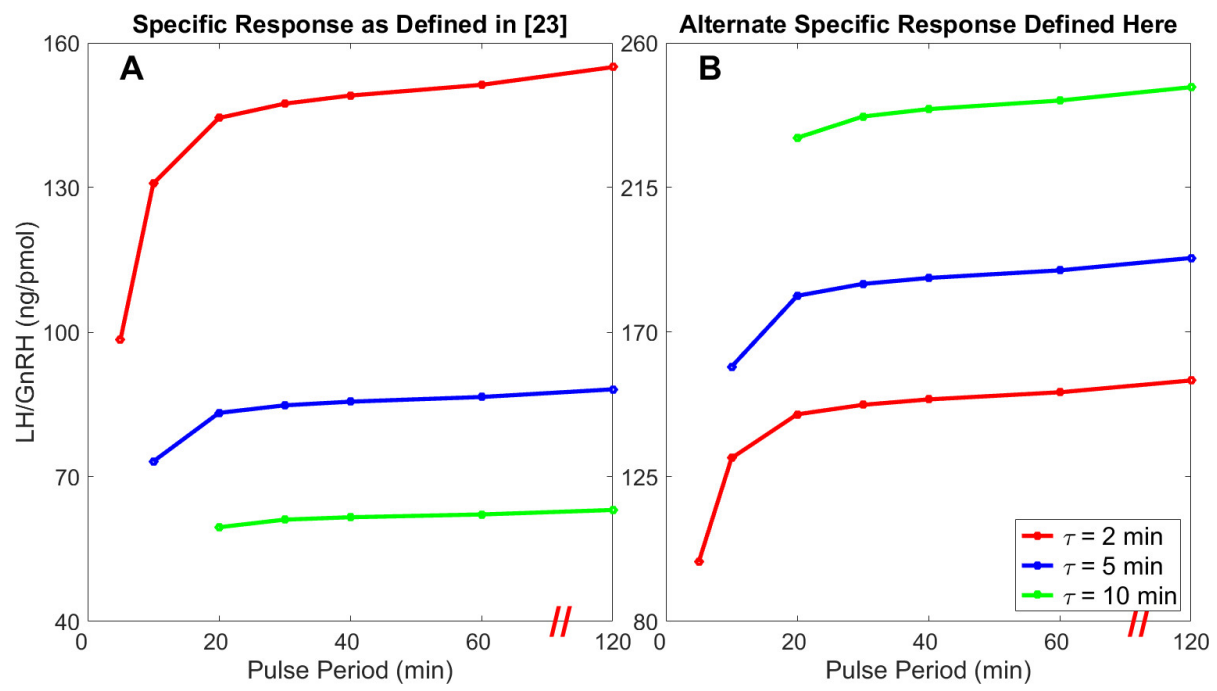

Figure 11: Specific Response with Varying Pulse Characteristics. The x-axes show pulse period in minutes; the $\mathrm{y}$-axes show the specific response in $\mathrm{ng} / \mathrm{pmol}$. Three different pulse durations, $\tau$, are considered: 2 minutes (red), 5 minutes (blue), and 10 minutes (green). The average LH output per pulse using the second, the third and the fourth pulses is calculated and then divided by the total GnRH amount supplied in one pulse. Panel A shows the case where $4.23 \mathrm{nM}$ GnRH is given with each pulse for every pulse duration. In Panel B, 4.23 $\mathrm{nM}$ GnRH is given for $\tau=2$ minutes, $1.692 \mathrm{nM} \mathrm{GnRH}$ for $\tau=5$ minutes, and $0.846 \mathrm{nM}$ GnRH for $\tau=10$ minutes, so that the total amount of GnRH given in each pulse is the same. Note that in Panels A and B the scales of y-axes are different and the red lines are the same. Long pulse durations are less efficient if the same GnRH concentration is supplied (Panel A); however, they are more efficient if the total GnRH amount per pulse is kept constant (Panel B).

into the chamber for different pulse characteristics, which they called the "specific response". To this end, they calculated the average LH output per pulse using the second, the third and the fourth pulses and then divided it by the total amount of GnRH given in each pulse. The total amount of GnRH per pulse depends on the GnRH concentration, the flow rate of the culture medium and the pulse duration $\tau$. Similarly, the average LH output per pulse depends on the concentration of the LH coming from the chamber, the flow rate of the culture medium and the GnRH pulse period. Since McIntosh et al. use the same GnRH concentration and the same flow rate to generate their data, they look at the effect of the GnRH input frequency on the specific response they define. However, the total amount of GnRH per pulse is different with each GnRH input frequency.

We calculated their specific response in our simulations; the results are presented in Figure 11, Panel A. The x-axis shows the pulse period in minutes and the y-axis shows the specific response in $\mathrm{ng} / \mathrm{pmol}$. The red line shows the specific response when the pulse duration $\tau=2$ minutes, the blue line when 
$\tau=5$ minutes and the green line when $\tau=10$ minutes. The parameters used in the simulations are from Section 3.1.2. The results show that, for a fixed pulse period, the specific response is higher when the pulse duration $\tau$ is shorter. For a fixed pulse duration $\tau$, as the time interval between the pulses increases, the specific response increases. These results reproduce qualitatively Figure 4 in [27].

Alternatively, one can calculate a different "specific response" by giving the same total GnRH amount in every pulse independent of the pulse duration $\tau$. To calculate the specific response with this alternative way, we kept the flow rate constant and adjusted GnRH concentration for pulse duration $\tau$ so that the total amount of GnRH delivered in each pulse is constant. To this end, we simulated the experiment with $4.23 \mathrm{nM}$ GnRH for the pulse duration 2 minutes, $1.692 \mathrm{nM} \mathrm{GnRH}$ for 5 minutes and $0.846 \mathrm{nM}$ for 10 minutes, so that each pulse delivers the same total amount of GnRH regardless of the pulse duration. Then we calculated the specific response by calculating the average LH output per pulse using the second, the third and the fourth pulses and then dividing it by the total GnRH amount. The results are presented in Figure 11, Panel B. Unlike Panel A, with this alternative definition, the specific response was higher with longer pulse duration $\tau$. Observe that in Figure 11 the panels $\mathrm{A}$ and $\mathrm{B}$ have different $\mathrm{y}$-axis scales and the red lines corresponding to $\tau=2$ minutes are the same lines.

Since the LH amount a cell can secrete is limited, using high GnHR concentrations does not lead to a proportional increase in the LH amount secreted. When $4.23 \mathrm{nM}$ or $0.846 \mathrm{nM}$ of GnRH is given for 10 minutes, the LH output at $x=\ell$ shows a triphasic response, where it first peaks and then decreases down to a quasi steady state level until the end of the GnRH stimulation. The quasi steady state LH level at $x=\ell$ is higher with $4.23 \mathrm{nM}$ GnRH compared to $0.846 \mathrm{nM} \mathrm{GnRH}$, but not 5 times higher. Thus, dividing the average LH output per pulse by the total GnRH given to the chamber resulted in a lower specific response with the $4.23 \mathrm{nM}$ stimulation compared to $0.846 \mathrm{nM}$.

Although McIntosh et al. concluded that with decreasing pulse duration the responsiveness of the cells is increased, our simulations suggest that long pulse durations with low GnRH concentrations lead to higher LH output per GnRH amount supplied.

\section{SENSITIVITY ANALYSIS}

To investigate how sensitive the characteristic triphasic response is to choices of parameter values, we vary the parameters up to $20 \%$. For every parameter we create a region with $20 \%$ lower and $20 \%$ higher than the particular parameter value and then we randomly pick the parameter from that region with a uniform distribution. We perturb all the parameters at the same time and generate 1000 


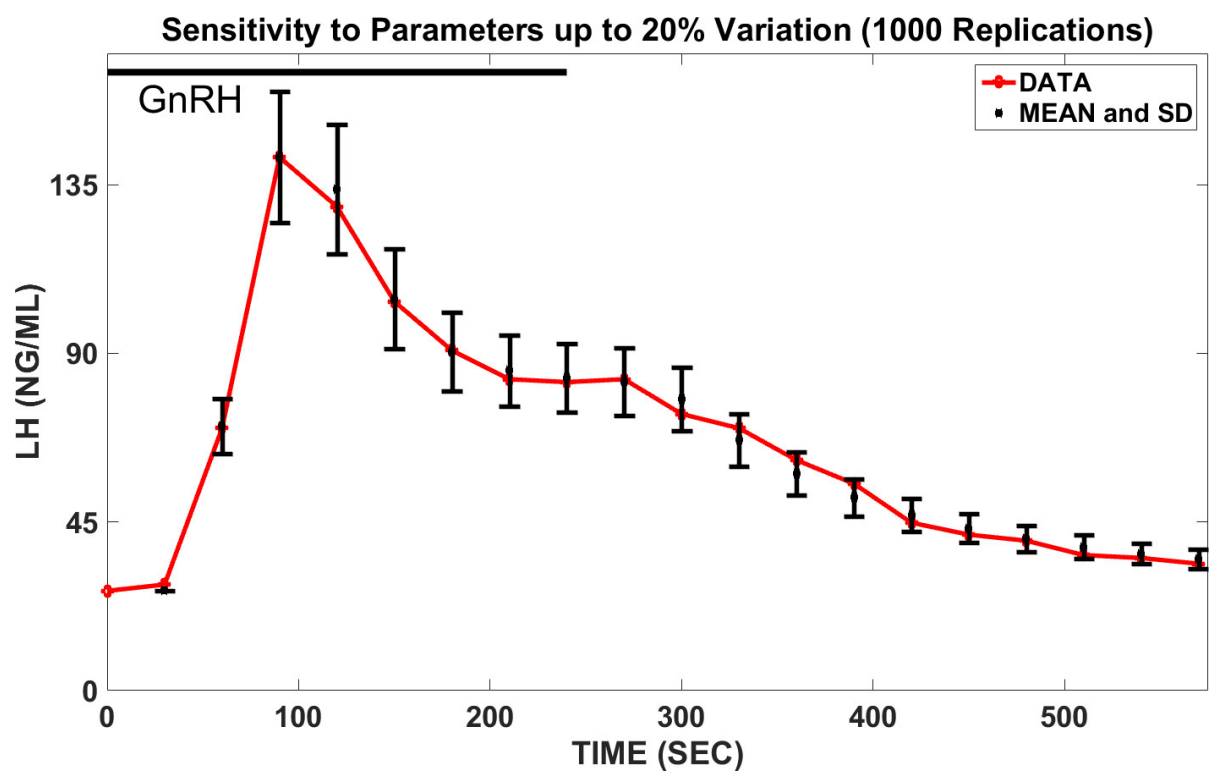

Figure 12: Sensitivity of LH outcome at $x=\ell$ to parameters. The parameters used for Section 3.1.1 are varied randomly up to $20 \%$ and 1000 simulations are run with perturbed parameters. The mean and the standard deviation for these 1000 runs are calculated and plotted with the data. The red dots and the line connecting them is the data from [26] and the black points and the black bars are the mean and the standard deviation of the 1000 simulations with perturbed parameters. The black bar at the top of the graph shows the GnRH stimulation. We see that the characteristic triphasic response is not sensitive to parameter choices and is preserved over a range of parameters.

runs with varied parameter and for each data point we calculate the mean and the standard deviation. In Figure 12 the red line shows the data from [26] and the black bars are centered at the mean of the 1000 runs, and the bars show the region within one standard deviation of the mean. The black bar at the top of the graph shows GnRH stimulation. The triphasic response is preserved even with the perturbed parameters, indicating that this characteristic shape of the response is not sensitive to parameters chosen.

\section{DISCUSSION}

Many hormones are secreted in pulses including GnRH, growth hormone, adrenocorticotropic hormone, oxytocin, insulin and glucagon [35]. Perifusion cell cultures permit the study of such intermittent stimulation in a controlled environment. Mathematical models are important tools for interpreting the results of these perifusion experiments and for connecting their outcomes to cellular events. 
With our mathematical model, we aim to couple the intracellular signaling events with the movement of substances in the perifusion chamber. We lack experimental data to model the intracellular events in detail. In the absence of data to constrain the model, adding more intracellular components would just add more parameters, and would make fitting the data easier. Instead of building a large model with too many free parameters, where determination of important dynamics would be impossible, we tried to grasp the essential dynamical properties of the system, which would explain all the data sets. Our mathematical model indicates that two negative feedback loops, one fast and one slow acting, are needed to explain the data. We suggest that the molecular basis of the fast acting negative feedback is the inhibition by the phosphatase downstream of the receptor and of the slow acting negative feedback is receptor desensitization.

Systems of ordinary differential equations model well static cell cultures, where cells are incubated in a well-mixed stationary medium. However, in perifusion cell cultures the medium is not homogeneous throughout the chamber and is constantly moving. The secreted products and the signal introduced into the chamber are constantly washed out. Thus, in order to interpret the perifusion data one must consider the spatial aspect of these experimental systems. In this paper we developed and analyzed a mathematical model of coupled partial differential equations for perifusion cell culture experiments, which combined the movement of the substances in the chamber with the intracellular events leading to LH secretion.

In Section 3.1 we matched the model to three different data sets and the model fit well to all of them. In Section 3.1.1 we determined the parameters to reproduce the data from [26] and in Section 3.1.2 we used the same parameters to reproduce the experiments from [27]. Thus, the second data set served as a cross validation for the choice of parameters. For the third data set from [28] we used a different set of parameters. That is biologically reasonable since the experimenters used a different cell type than the other two groups.

In Section 3.1.1 we analyzed the triphasic LH response at $x=\ell$, which consisted of the LH peak, followed by the lower quasi steady state level and the decrease back to the basal secretion level. The negative feedback from the phosphatases was crucial in reaching the lower quasi steady state LH level at $x=\ell$. Receptor desensitization did not have a significant effect, since the data was collected over a relatively short time interval. In our model, the rate of return to the basal LH level at $x=\ell$ depended primarily on the dissociation rate of bound $\mathrm{GnRH}$ from its receptor, $k_{2}$.

In Section 3.1.2 the data from [27] was collected over 480 minutes. The receptor desensitization led to the eventual suppression of the LH secretion in this prolonged GnRH exposure. The simulations of the first two data sets show that the phosphatase based negative feedback is fast and important over short 
time intervals, whereas GnRH receptor desensitization affects the outcome over long time intervals. This is consistent with the literature, as GnRH-R does not undergo rapid homologous desensitization as most other $\mathrm{G}$ protein-coupled receptors, but the downstream post-receptor desensitization mechanisms operate on a faster time scale $[17,36]$. Note that in the third row of Figure 5, the second GnRH pulse leads to a higher response than the first pulse both in the simulation and in the data. Also the heights of the LH outcome vary throughtout the $\mathrm{GnRH}$ stimulation. In the simulation, this variation depends solely on the fraction collection time: fraction collection times that do not divide the period of the stimulation evenly lead to irregularities in the data. To differentiate between the artifacts of sampling and interesting biological phenomena, the medium collection time should be chosen so that it divides the period of the stimulation evenly and it should be fine enough to capture the different phases of the LH secretion pattern. Of course, if one samples very frequently, then it is not necessary that the fraction collection time divides the period evenly. However, the LH amount collected in very short fraction collection times may be very small and therefore not easy to detect and possibly prone to errors.

Some irregularity in the data might also come from priming. Increased sensitivity of gonadotrophs to subsequent GnRH pulses is called self-priming [37]. Our model lacks the biological mechanisms which might be responsible for priming such as the integration of the fast $\mathrm{Ca}^{2+}$-mediated pathway and the slow cAMP-mediated processes [23, 38], exposure to estrogen [37], the autocrine affects of pituitary derived GnRH [39], and repositioning of secretory granules to cell membrane through microfilament reorientation [40].

The data set from [28] compared the GnRH and oxytocin stimulation in rat pituitary cells. GnRH and oxytocin receptors are both G-protein coupled receptors connected to the same downstream effectors, however, unlike GnRH receptors, oxytocin receptors can undergo rapid desensitization [41]. After choosing the parameters to match our model to GnRH stimulation data, we reproduced the oxytocin stimulation results by altering only one or two parameters related to receptor dynamics and keeping the rest of the parameters the same. Thus, we showed that different receptor dynamics might underlie the difference in the $\mathrm{GnRH}$ and oxytocin experimental results.

In Section 3.2, we conducted in silico experiments to explore the influence of some key parameters on data. In Section 3.2.1, we showed that with slow velocities the time required to reach the steady state basal LH level at $x=\ell$ is longer and the LH content of the outgoing medium is higher. One might think that in case of slow velocities the autocrine signals are not washed out, leading to higher secretion [39]. To differentiate between biological effects and the influence of medium flow velocity, one should calculate the increase in the LH levels due to lowering the medium flow velocity and if the effect seen is more prominent than expected, then one should look for biological explanations. 
In Section 3.2.2 we focused on the movement of GnRH down the chamber. High binding rate, $k_{1}$, low dissociation rate, $k_{2}$, and high total GnRH receptor concentration lead to high bound GnRH levels, thus more production of LH, and also slower movement of GnRH down the column. This suggests an inverse mathematical problem and a possible technique for determining binding and dissociation constants: the substance whose binding and dissociation rates are to be determined can be passed through a column with a known receptor concentration. By carefully sampling the outflow, one can determine the rate constants. This approach was used in [42] and [43].

In Section 3.2.3 we investigated the dependence of the LH secretion amount on the pulse characteristics. In [27] the notion of "specific response" was introduced, which is calculated by dividing the average LH output per pulse by the total amount of GnRH introduced in one pulse. They found that short pulse durations $\tau$ with long in between pulse intervals was the most efficient way of stimulation. Our simulations reproduced their results. However, we suggested an alternative definition of "specific response". In [27] the total amount of GnRH introduced into the chamber in one pulse depended on the pulse duration $\tau$, where long pulses resulted in high total GnRH amount per pulse. In our alternative definition we keep the GnRH amount per pulse the same independent of the pulse duration $\tau$. Our simulations indicate that longer pulses with lower GnRH concentrations are more efficient than high concentration short duration pulses.

Our mathematical model can be expanded to incorporate more downstream elements relevant to the production of $\mathrm{LH}$, like the $\mathrm{IP}_{3}$ and DAG pathway [10]. Also, our methods can be used to understand perifusion experiments for other hormones by including relevant cellular mechanisms for their signaling pathways. In addition, for experimental systems with very slow velocities or small $\ell$, a Laplacian term can be added to the equations for free GnRH (1a) and LH (1f) to incorporate diffusive effects.

\section{ACKNOWLEDGMENTS}

This work was supported by grants R01 ES019876 from NIH (HFN, MCR) and EF-1038593 from NSF (MCR,HFN) and D12AP00001 (J Harer) from DARPA.

\section{REFERENCES}

[1] JEFFREY Weiss, WILLIAM F Crowley Jr, LISA M Halvorson, and J LARRY Jameson. Perifusion of rat pituitary cells with gonadotropinreleasing hormone, activin, and inhibin reveals distinct effects on gonadotropin gene expression and secretion. Endocrinology, 132(6):23072311, 1993. 
[2] Gregoy Y Bedecarrats and Ursula B Kaiser. Differential regulation of gonadotropin subunit gene promoter activity by pulsatile gonadotropinreleasing hormone (gnrh) in perifused l $\beta$ t2 cells: role of gnrh receptor concentration. Endocrinology, 144(5):1802-1811, 2003.

[3] Indri N Purwana, Haruhiko Kanasaki, Aki Oride, and Kohji Miyazaki. Induction of dual specificity phosphatase 1 (dusp1) by gonadotropin-releasing hormone (gnrh) and the role for gonadotropin subunit gene expression in mouse pituitary gonadotroph lbetat2 cells. Biology of reproduction, 82(2):352-362, 2010.

[4] Ghislaine Garrel, Violaine Simon, Marie-Lise Thieulant, Xavier Cayla, Alphonse Garcia, Raymond Counis, and Joëlle Cohen-Tannoudji. Sustained gonadotropin-releasing hormone stimulation mobilizes the camp/pka pathway to induce nitric oxide synthase type 1 expression in rat pituitary cells in vitro and in vivo at proestrus. Biology of reproduction, 82(6):1170-1179, 2010 .

[5] Joshua G Pemberton, Michael E Orr, James L Stafford, and John P Chang. Pi3k signalling in gnrh actions on dispersed goldfish pituitary cells: relationship with pkc-mediated $\mathrm{lh}$ and gh release and regulation of long-term effects on secretion and total cellular hormone availability. General and comparative endocrinology, 205:268-278, 2014.

[6] DJ Haisenleder, LL Burger, HE Walsh, J Stevens, KW Aylor, MA Shupnik, and JC Marshall. Pulsatile gonadotropin-releasing hormone stimulation of gonadotropin subunit transcription in rat pituitaries: evidence for the involvement of jun n-terminal kinase but not p38. Endocrinology, 149(1):139-145, 2008.

[7] John J Evans, Fiona L Pragg, and Drusilla R Mason. Release of luteinizing hormone from the anterior pituitary gland in vitro can be concurrently regulated by at least three peptides: gonadotropin-releasing hormone, oxytocin and neuropeptide y. Neuroendocrinology, 73(6):408-416, 2001.

[8] RP McIntosh and JEA McIntosh. Dynamic characteristics of luteinizing hormone release from perifused sheep anterior pituitary cells stimulated by combined pulsatile and continuous gonadotropin-releasing hormone*. Endocrinology, 117(1):169-179, 1985.

[9] Zvi Naor, Outhiriaradjou Benard, and Rony Seger. Activation of mapk cascades by g-protein-coupled receptors: the case of gonadotropin-releasing hormone receptor. Trends in Endocrinology Eamp; Metabolism, 11(3):9199, 2000 .

[10] Frederique Ruf and Stuart C Sealfon. Genomics view of gonadotrope signaling circuits. Trends in Endocrinology Eamp; Metabolism, 15(7):331-338, 2004 . 
[11] Rebecca M Perrett and Craig A McArdle. Molecular mechanisms of gonadotropin-releasing hormone signaling: integrating cyclic nucleotides into the network. Frontiers in endocrinology, 4, 2013.

[12] Varykina G Thackray, Pamela L Mellon, and Djurdjica Coss. Hormones in synergy: regulation of the pituitary gonadotropin genes. Molecular and cellular endocrinology, 314(2):192-203, 2010.

[13] T Zhang and MS Roberson. Role of map kinase phosphatases in gnrhdependent activation of map kinases. Journal of molecular endocrinology, $36(1): 41-50,2006$.

[14] Nick A Ciccone and Ursula B Kaiser. The biology of gonadotroph regulation. Current opinion in endocrinology, diabetes, and obesity, 16(4):321, 2009 .

[15] Haruhiko Kanasaki, Indri Purwana, Aki Oride, Tselmeg Mijiddorj, and Kohji Miyazaki. Extracellular signal-regulated kinase (erk) activation and mitogen-activated protein kinase phosphatase 1 induction by pulsatile gonadotropin-releasing hormone in pituitary gonadotrophs. Journal of signal transduction, 2012, 2011.

[16] Iain R Thompson and Ursula B Kaiser. Gnrh pulse frequency-dependent differential regulation of $\mathrm{lh}$ and fsh gene expression. Molecular and cellular endocrinology, 385(1):28-35, 2014.

[17] Craig A McArdle, J Franklin, L Green, and JN Hislop. Signalling, cycling and desensitisation of gonadotrophin-releasing hormone receptors. Journal of Endocrinology, 173(1):1-11, 2002.

[18] Masha Dobkin-Bekman, Michal Naidich, Adam J Pawson, Robert P Millar, Rony Seger, and Zvi Naor. Activation of mitogen-activated protein kinase (mapk) by gnrh is cell-context dependent. Molecular and cellular endocrinology, 252(1):184-190, 2006.

[19] WR Smith, GC Wake, JE McIntosh, RP McIntosh, M Pettigrew, and R Kao. Mathematical analysis of perifusion data: models predicting elution concentration. American Journal of Physiology-Regulatory, Integrative and Comparative Physiology, 261(1):R247-R256, 1991.

[20] John C Magill, Nick A Ciccone, and Ursula B Kaiser. A mathematical model of pulse-coded hormone signal responses in pituitary gonadotroph cells. Mathematical biosciences, 246(1):38-46, 2013.

[21] J Joseph Blum, Michael C Reed, Jo Ann Janovick, and P Michael Conn. A mathematical model quantifying gnrh-induced lh secretion from gonadotropes. American Journal of Physiology-Endocrinology And Metabolism, 278(2):E263-E272, 2000. 
[22] Talitha M Washington, J Joseph Blum, Michael C Reed, and P Michael Conn. Theoretical biology and medical modelling. Theoretical Biology and Medical Modelling, 1:9, 2004.

[23] JJ Evans, TM Wilkinson, and DJN Wall. A two-pathway mathematical model of the $\mathrm{lh}$ response to gnrh that predicts self-priming. International journal of endocrinology, 2013, 2013.

[24] Richard Bertram and Yue-Xian Li. A mathematical model for the actions of activin, inhibin, and follistatin on pituitary gonadotrophs. Bulletin of mathematical biology, 70(8):2211-2228, 2008.

[25] K Heinze, RW Keener, and AR Midgley. A mathematical model of luteinizing hormone release from ovine pituitary cells in perifusion. American Journal of Physiology-Endocrinology and Metabolism, 275(6):E1061-E1071, 1998.

[26] HC Cantor, VASANTHA Padmanabhan, PAUL A Favreau, and AR Midgley Jr. Use of newly designed microperifusion system with amperometric sensors for near-continuous on-line monitoring of hormone secretion. i. correlation with the luteinizing hormone secretory response to gonadotropinreleasing hormone. Endocrinology, 137(7):2782-2790, 1996.

[27] JEA McIntosh and RP McIntosh. Varying the patterns and concentrations of gonadotrophin-releasing hormone stimulation does not alter the ratio of $\mathrm{lh}$ and fsh released from perifused sheep pituitary cells. Journal of endocrinology, 109(2):155-161, 1986.

[28] Arturo E Gonzalez-Iglesias, Patrick A Fletcher, José A Arias-Cristancho, Ruth Cristancho-Gordo, Cleyde V Helena, Richard Bertram, and Joël Tabak. Direct stimulatory effects of oxytocin in female rat gonadotrophs and somatotrophs in vitro: comparison with lactotrophs. Endocrinology, 156(2):600-612, 2014.

[29] Ronald L Fournier. Basic transport phenomena in biomedical engineering. CRC Press, 2011.

[30] Nadja Heinrich, Dorothea Lorenz, Hartmut Berger, Klaus Fechner, Hermann Eberhard Schmidt, Heinz Schäfer, and Burkhard Mehlis. Effect of dextran on the release of gonadotropin-releasing hormone (gnrh) injected into rats: Plasma gnrh and gonadotropin response. Pharmaceutical research, 2(5):198-202, 1985.

[31] Choh Hao Li and Kai O Pedersen. Physicochemical characterization of pituitary follicle-stimulating hormone. The Journal of general physiology, 35(4):629-637, 1952.

[32] AR Midgley, RM Brand, PA Favreau, BG Boving, MN Ghazzi, V Padmanabhan, EY Young, and HC Cantor. [8] monitoring dynamic responses 
of perifused neuroendocrine tissues to stimuli in real time. Methods in Neurosciences, 28:188-219, 1995.

[33] JEA McIntosh, RP McIntosh, and RJ Kean. Microcomputer-controlled device for delivering hormone stimulation to cell suspensions in perifusion: release of luteinising hormone from sheep pituitary cells. Medical and Biological Engineering and Computing, 22(3):259-262, 1984.

[34] RP Murray-McIntosh and JE Alister McIntosh. Modeling pulsatile hormone stimulation of cell responses. METHODS IN NEUROSCIENCESLONDON-, 20:423-423, 1994.

[35] Johannes D Veldhuis, Daniel M Keenan, and Steven M Pincus. Motivations and methods for analyzing pulsatile hormone secretion. Endocrine Reviews, 29(7):823-864, 2008.

[36] Craig A McArdle, James S Davidson, and Gary B Willars. The tail of the gonadotrophin-releasing hormone receptor: desensitization at, and distal to, g protein-coupled receptors. Molecular and cellular endocrinology, 151(1):129-136, 1999.

[37] Gareth Leng, Celine Caquineau, and Mike Ludwig. Priming in oxytocin cells and in gonadotrophs. Neurochemical research, 33(4):668-677, 2008.

[38] John J Evans. Modulation of gonadotropin levels by peptides acting at the anterior pituitary gland. Endocrine reviews, 20(1):46-67, 1999.

[39] Lazar Z Krsmanovic, Antonio J Martinez-Fuentes, Krishan K Arora, Nadia Mores, Melanija Tomić, Stanko S Stojilkovic, and Kevin J Catt. Local regulation of gonadotroph function by pituitary gonadotropin-releasing hormone. Endocrinology, 141(3):1187-1195, 2000.

[40] S Scullion, D Brown, and G Leng. Modelling the pituitary response to luteinizing hormone-releasing hormone. Journal of neuroendocrinology, 16(3):265-271, 2004.

[41] Gerald Gimpl and Falk Fahrenholz. The oxytocin receptor system: structure, function, and regulation. Physiological reviews, 81(2):629-683, 2001.

[42] Michael C Reed and J Blum. Mathematical questions in axonal transport. In Cell Biology: 1992 Symposium on Some Mathematical Questions in Biology, Lectures in Mathematics in the Life Sciences, volume 24, page 1, 1994.

[43] Michael C Reed, Stephanos Venakides, and Jacob Joseph Blum. Approximate traveling waves in linear reaction-hyperbolic equations. SIAM Journal on Applied Mathematics, 50(1):167-180, 1990. 